\title{
Blink reflexes and the state of arousal
}

\author{
A. J. W. BOELhOUWER AND C. H. M. BRUNiA \\ From Tilburg University, Department of Psychology, Physiological Psychology Section, Tilburg, The Netherlands
}

SUMMARY Blink reflexes were studied in 40 subjects at rest and during the performance of a task. The early reflex (R1) showed an increase of amplitude of action potential during the task, the late reflex (R2) did not. The latency of R1 did not change within the 45 minute test period; 22 showed an increase of latency during task. R1 showed a systematic decrease in amplitude within rest and task periods, presumably because of habituation. R2 amplitudes decreased throughout the whole experiment, independent of task or rest.

Activation, due to the performance of a mental task, can be measured by several physiological parameters. Two types of recordings are generally used: first, registration of spontaneous activity of the organism in different circumstances as, for example, heart rate or skin resistance; secondly, recording of changes in responses after certain stimuli, evoked responses in EEG and reflexes being an example of the second kind. After the work of Paillard (1955) many experiments have been done using the amplitude of muscle action potentials evoked by a monosynaptic reflex to estimate the excitability of motoneurones. Differentiating effects have been obtained with different reflexes during a task. The action potential amplitude of tendon reflexes (TR) increased during the performance of a task, whereas Hoffmann reflexes (HR) did not, pointing to a lack of alpha-gamma coactivation (Brunia, 1971). With increasing time on a task, a systematic smaller increase in amplitude of TR has also been recorded and has been interpreted as a habituation phenomenon. Polysynaptic reflexes have also been investigated. Bathien (1971) found an increase of polysynaptic flexion reflexes in the biceps femoris muscle while performing a task.

Blink reflexes show striking similarities with flexor reflexes in general (Shahani, 1968; Shahani and Young, 1972). They consist of two components, an ipsilateral early reflex (R1) and a bilateral late reflex (R2). Although the discussion on the extero- or proprioceptive nature of the first component is not closed definitively, the majority of the arguments are in favour of the first possibility (Shahani, 1968; Shahani and Young, 1968; Penders and Delwaide, 1973).

$\mathrm{R} 1$ is oligo-, $\mathrm{R} 2$ polysynaptic and $\mathrm{R} 2$ especially decreases in amplitude and duration after repeated stimulation. This so-called habituation is maximal if Accepted 9 September 1976 subjects are allowed to evoke their own blink reflexes (Shahani and Young, 1972). Gregorič (1973) states that $\mathrm{R} 1$ does not habituate at all. There are strong indications that the magnitude of the blink reflex depends on the vigilance level of the organism. Amplitudes are smaller during synchronised sleep (Ferrari and Messina, 1972; Kimura and Harada, 1972). Moreover, blink reflexes are diminished or absent during comatose states (Kimura, 1973) and blinking plays an important role in the so-calledo orientation reaction (Sokolov, 1963). Shahani and Young (1972) mention that fear, unrelated to theg stimulus, causes an increase of $\mathrm{R} 2$. The same reaction is mentioned by Penders and Delwaide (1973) during stress and arithmetical calculation tasks.' Gregorič (1973) reports a slower habituation when attention is distracted from the stimulation. No systematic research on the reaction of the blink reflex during mental tasks has yet been done. Activation and habituation effects are, however, indicated in the literature. In the present experiment the task previously used by Brunia (1971) has been employed.

\section{Methods}

The experiment included two different series. Forty healthy volunteer students of both sexes were used, 20 subjects in each series. Subjects sat in a comfortable chair in a shielded soundproof cabin. Both experimental series were subdivided into three periods: the first had 10 minutes rest, 20 minutes task and 10 minutes rest; the second had 10 minutes task, 20 minutes rest, and 10 minutes task. During the task periods subjects performed an auditory binary choice task. High $(2400 \mathrm{~Hz})$ and low $(800 \mathrm{~Hz})$ tones were presented in random order via a loudspeaker, using a frequency of 70 tones per minute. Two response buttons were located on the arms of the chair. 
Subjects were instructed to press the right button when they heard the high tone and the left when they heard the low tone. The tones were not related to the electrical stimuli.

Electrical stimulation was applied using a Grass S88 stimulator and a Grass CCU 1A constant current unit. Two $\mathrm{Ag}-\mathrm{AgCl}$ surface electrodes (EEG type) were placed on the left side of the forehead: the cathode on the supraorbital branch of the trigeminal nerve, the anode about $1 \mathrm{~cm}$ above this. The stimulation frequency was $1 / 7 \mathrm{~s}$, and the duration $0.1 \mathrm{~ms}$. Shock intensity differed for individual subjects so that R1 was maximal and approximately stable during 10 test stimuli with the chosen stimulation frequency. EMG responses were recorded by means of two $\mathrm{Ag}-\mathrm{AgCl}$ surface electrodes placed on the medial portion of the left orbicularis oculi inferior muscle and on the left side of the nasal bone.

The responses were amplified by a Hellige EE preamplifier and recorded on a Hewlett-Packard instrumentation recorder (type HP3960, recording velocity $15 / 16 \mathrm{inch} / \mathrm{s}$ ). Trigger-pulses from the stimulator were recorded on the second channel. Both the response and the trigger-pulse were monitored during the experiments on a Tektronix oscilloscope (single beam, type 5106/D10 with option P7).

The EMG of every seventh response was digitalised off-line using a DEC Lab 8/e computer. The sample frequency was $5 \mathrm{kHz}$. The digitalised signal was displayed graphically and by means of cursors the latency of R2 could be measured. Using a datacommunication system, the digitalised responses were sent to a DEC PDP 11/45 computer for final calculations. After trend removal to correct for possible baseline drift, the latency of $\mathrm{R} 1$, the maximum peak-peak amplitude and the integral (full wave rectification) of both $\mathrm{R} 1$ and $\mathrm{R} 2$ were calculated. For each parameter, means and standard deviations per subject were computed over periods of five minutes. Means were transformed to standard z-scores for every subject. Mean z-scores of 20 subjects were computed, as were the concomitant 0.95 confidence limits. Student's $t$ test for two dependent groups was used to investigate the differences between task and rest for all measured parameters.

\section{Results}

Results are summarised in Figs. 1 and 2 and the Table. Because the curves of the action potential amplitudes and the integral of the reflexes are approximately the same, the latter are not shown.

EARLY REFLEX

In both series the action potential amplitude is larger during the task period (Figs. 1 and 2). This resttask difference is significant $(\mathrm{P}<0.01)$. Similar results have been observed for the integrated amplitudes, where the task scores are also significantly larger than the rest values. There is no significant task-rest difference for the latency of R1 (Table).

The amplitudes show a systematic decrease over time within both rest and task periods.

\section{LATE REFLEX}

In both series no task-rest differences have been observed for the action potential amplitude. The latency is always significantly prolonged during the task periods (Figs. 1 and 2 and Table).

The amplitude shows a systematic decrease over time in both series throughout the whole experiment, and not only within each rest and task condition as has been observed with R1. Almost no difference can be observed between the curves of series 1 and 2 . The latency shows a continuous increase within both the rest and task periods, excluding the last five minutes of the rest period in series 2 .

\section{Discussion}

Any performance presupposes a certain arousal level apart from the specific demands of the task under consideration. The increase of the amplitude of the early reflex is most likely to be an indication of a shift of the arousal level. So it is presumably part of a more general disinhibition or facilitation of the different motoneurone pools in the brainstem and spinal cord. An increase of monosynaptic reflex amplitudes has been previously mentioned by Bathien (1971) using different tasks, and also by Brunia (1971) using the same task. As far as monosynaptic reflexes are concerned, a differentiating effect of a task on $H$ and $T$ reflexes has been found (Bathien, 1971; Brunia, 1971). The only explanation of the results found by Brunia seems to be a lack of alpha-gamma coactivation (to be discussed elsewhere). Polysynaptic reflexes again show differentiating effects of tasks. Thus Bathien (1971) mentions an amplitude increase of the early component for a polysynaptic flexion reflex, without any change of the late response. This is in agreement with the R1 data presented in this paper. So the similarity of the organisation of the blink reflex and the flexion reflex, mentioned by Shahani (1968), holds also for the changes during arousal. It seems worth while to use the blink reflex because there is at least one aspect in which this does not follow the general reaction pattern of most reflexes. Beck et al. (1973) and Kimura and Harada (1972) mention a decrease of blink reflex amplitudes in sleep which agrees with other reflex data (Hodes and Dement, 1964). In stage REM, however, when 


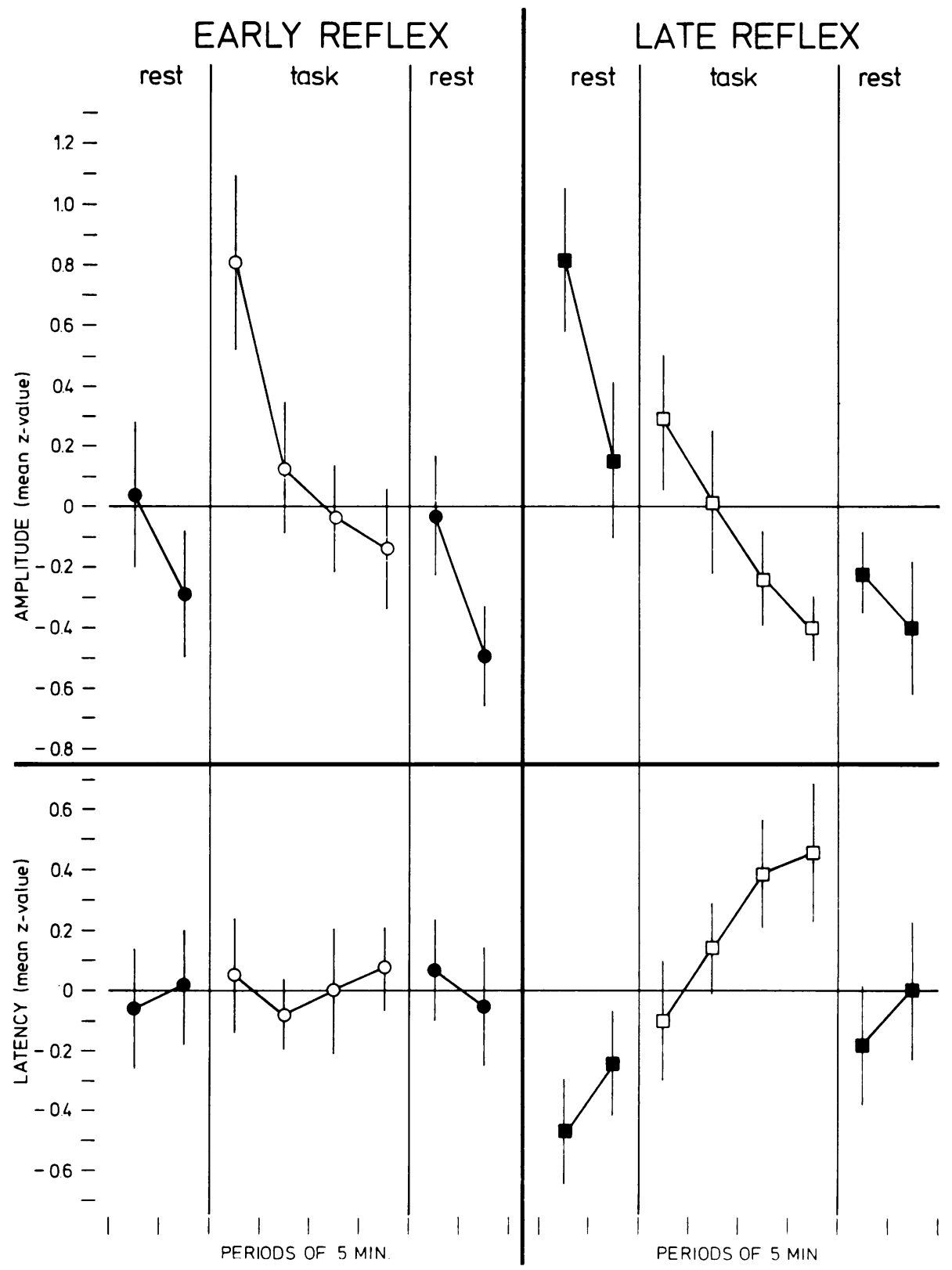

Fig. 1 Amplitudes and latencies of $R 1$ and $R 2$ action potentials during the first experimental series (see text), averaged over five minute periods (20 subjects). Vertical lines indicate the 0.95 confidence intervals.

other reflexes have their smallest amplitudes, blink reflex amplitudes increase again.

Although the motor control of the blink reflex seems to be different from spinal reflexes in sleep, $\mathrm{R} 1$ follows the general activation pattern of monosynaptic reflexes and first components of poly- synaptic reflexes. $\mathrm{R} 2$ shows no effect of the arousal shift. The only finding is a continuously decreasing amplitude throughout the whole experiment. Presumably because of a greater number of synapses involved in the reflex arc of R2, a clear effect of the task cannot be expected. This is the more so as there 


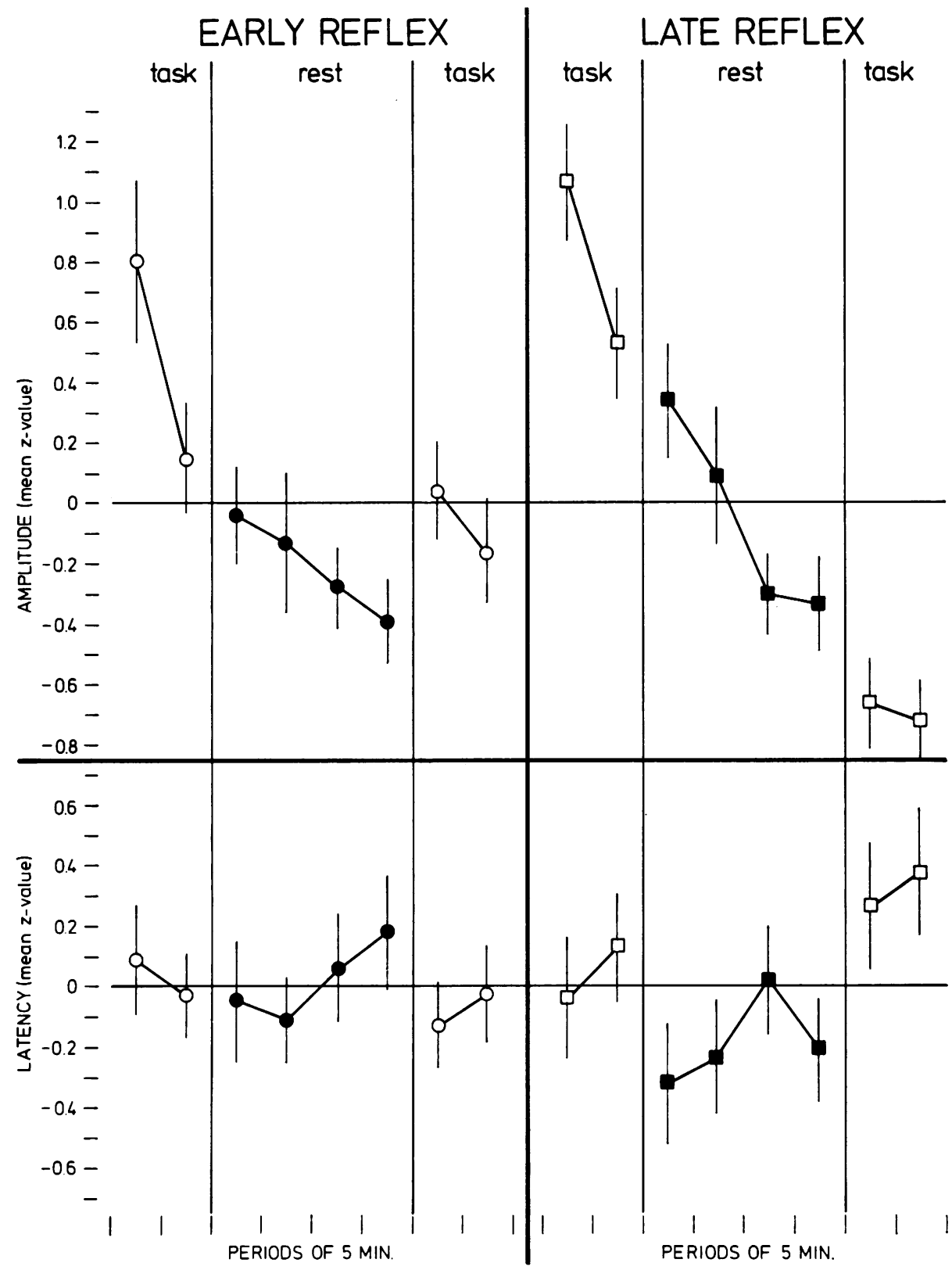

Fig. 2 Amplitudes and latencies of $R 1$ and $R 2$ during the second experimental series (see text), averaged over five minute periods (20 subjects). Vertical lines indicate the 0.95 confidence intervals.

is no direct relation between the specific systems activated to perform the task and the neural connections of the blink reflex. If a blink should be the demanded response to a given signal-for example, a tone-so that the output channel of the task is the same as that of the blink reflex, a more specific effect might be expected. Requin (1969) and Gerilovsky and Tsekov (1975) have already carried out similar experiments with monosynaptic reflexes. In the near future we hope to present such data on the blink reflex as well.

The latency of R1 does not show any systematic 
Table Student's t test values (two-tailed) of the integral, amplitude and latency for $R I$ and $R 2$ in both experimental series (rest minus task)

\begin{tabular}{lll}
\hline & \multicolumn{1}{l}{ Blink reflex } & \\
\cline { 2 - 3 } & Early & Late \\
\hline Series I (rest-task-rest) & & \\
Integral & $-3.04^{*}$ & +0.78 \\
Amplitude & $-3.18^{*}$ & +1.49 \\
Latency & $-0.30^{*}$ & $-3.94^{*}$ \\
Series II (task-rest-task) & $-5.56^{*}$ & -1.17 \\
Integral & $-4.56^{*}$ & -0.92 \\
Amplitude & +0.68 & $-3.46^{*}$ \\
Latency & & \\
\hline
\end{tabular}

$t$ values (rest-task).

${ }^{*} \mathrm{p}<0.01$.

differences between rest and task. Action potential amplitudes increase during the task. Thus our results indicate no correlation between latency and amplitude. This is contrary to the findings of Macarez and Henane $(1974,1975)$, who mention that in most of their subjects there was a negative correlation between the above-mentioned parameters in both $\mathrm{H}$ and $\mathrm{T}$ reflexes. $\mathrm{R} 2$ latency is larger during the task than at rest in both series. The presentation of the task is supposed to have caused a shift in the arousal level and-at least in the first experimental seriesa change in the ongoing habituation. If anything, one would expect a smaller latency of R2 during the task than at rest, and also a systematic increase during the task. In fact we found a larger latency during the task. Indeed a systematic increase was found within the task period together with a systematic decrease of R2 amplitudes (Fig. 1). So our results are in agreement with those of Macarez and Henane for monosynaptic reflexes only during the task period in our first series.

Most authors agree on habituation of R2, but Gregorič (1973), in an investigation of habituation of the blink reflex, denies this phenomenon for R1. Our data show a systematic decrease of $R 1$ amplitudes within both the rest and task situation. We think that this is due to habituation, although it does not meet all the criteria of Thompson and Spencer (1966).

The systematic decrease of amplitudes at rest will be more easily accepted as habituation than the same phenomenon during the performance of a task. Nevertheless, we are prepared to interpret our data during the task in the same way. A more detailed discussion on the differences and similarities between decrease of activation versus habituation is beyond the scope of this paper. For the time being, a decrease of activation is a less controversial interpretation of our data.
The authors wish to thank F. J. J. van Bussel (Department of Psychology, Tilburg) for the development of the computer programs and Henri de Haan for his assistance throughout the experiments.

\section{References}

Bathien, N. (1971). Réflexes spinaux chez l'homme et niveaux d'attention. Electroencephalography and Clinical Neurophysiology, 30, 32-37.

Beck, U., Schenk, E., and Ischinger, Th. (1973). Spinale und bulbäre Reflexe im Schlaf beim Menschen. Archiv für Psychiatrie und Nervenkrankheiten, 217, 157-168.

Brunia, C. H. M. (1971). The influence of a task on the Achilles tendon and Hoffmann reflex. Physiology and Behavior, 6, 367-373.

Ferrari, E., and Messina, C. (1972). Blink reflexes during sleep and wakefulness in man. Electroencephalography and Clinical Neurophysiology, 32, 55-62.

Gregorič, M. (1973). Habituation of the blink reflex (role of selective attention). In New Developments in Electromyography and Clinical Neurophysiology, vol. 3, pp. 673-677. Edited by J. E. Desmedt. Karger: Basel.

Gerilovsky, L., and Tsekov, Ts. (1975). Changes in the excitability of the segmental apparatus for reciprocal inhibition of agonist during a fixed waiting period. Agressologie, 16, 233-236.

Hodes, R., and Dement, W. C. (1964). Depression of electrically induced reflexes (H-reflexes) in man during low voltage EEG-sleep. Electroencephalography ando Clinical Neurophysiology, 17, 617-629.

Kimura, J. (1973). The blink reflex as a test for brain-stem and higher central nervous system function. In News Developments in Electromyography and Clinical Neurophysiology, vol. 3, pp. 682-691. Edited by J. E. Desmedt.? Karger: Basel.

Kimura, J., and Harada, O. (1972). Excitability of the orbicularis oculi reflex in all night sleep: its suppression in non-rapid eye movement and recovery in rapid eye movement sleep. Electroencephalography and Clinical Neurophysiology, 33, 369-377.

Macarez, J. A., and Henane, R. (1974). Relation entre l'amplitude et la latence des réflexes monosynaptiques chez l'Homme: I. Etude sur la réponse T. Comptes Rendus des Séances de la Société de Biologie, 168, 981-985.

Macarez, J. A., and Henane, R. (1975). Relation entre l'amplitude et la latence des réflexes monosynaptiques chez l'Homme: 2. Etude sur les réponses $\mathbf{H}$. et $\mathbf{M}$. Comptes Rendus des Séances de la Société de Biologie, 169, 1214-1219.

Paillard, J. (1955). Réflexes et Régulations d'Origine Proprioceptive chez l'Homme. Arnette: Paris.

Penders, C. A., and Delwaide, P. J. (1973). Physiologic approach to the human blink reflex. In New Developments in Electromyography and Clinical Neurophysio$\log y$, vol. 3, pp. 649-657. Edited by J. E. Desmedt. Karger: Basel.

Requin, J. (1969). Some data on neurophysiological processes involved in the preparatory motor activity to reaction time performance. In Attention and Perfor- 
mance II. Proceedings of the Donders Centenary Symposium on Reaction Time, Eindhoven (1968). Acta Psychologica, 30, 358-367.

Shahani, B. T. (1968). Effects of sleep on human reflexes with a double component. Journal of Neurology, Neurosurgery, and Psychiatry, 31, 574-579.

Shahani, B. T., and Young, R. R. (1968). A note on blink reflexes. Journal of Physiology. 198, 103-104.
Shahani, B. T., and Young, R. R. (1972). Human orbicularis oculi reflexes. Neurology (Minneap.), 22, 149-154.

Sokolov, Y. N. (1963). Perception and the Conditioned Reflex. Pergamon: Oxford.

Thompson, R. F., and Spencer, W. A. (1966). Habituation: A model phenomenon for the study of neuronal substrates of behaviour. Psychological Review, 73, 16-43. 